Indexed by

\title{
Scopus
}

\section{RESEARCH AND QUALITY ASSURANCE OF THE LARGE VALVES MANUFACTURE FOR TRUNK PIPELINES}

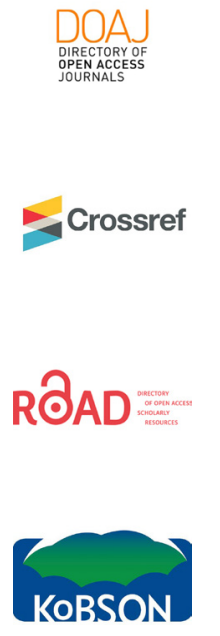

Riza Gabdyssalyk

D. Serikbayev East Kazakhstan State University, Department of mechanical engineering, Ust-Kamenogorsk, Kazakhstan

\section{Olga Zharkevich}

Karaganda State Technical University, Department of Technological equipment, mechanical and standardization, Karaganda, Kazakhstan

\section{Aizhan Taskarina \\ Toraigyrov University, Mechanical Engineering faculty, Department of Metallurgy, Pavlodar city, Kazakhstan}

\author{
Karibek Sherov \\ Karaganda State Technical \\ University, Department of \\ Technological equipment, \\ mechanical and standardization, \\ Karaganda, Kazakhstan
}

\section{Sergey Mirgorodskiy}

D. Serikbayev East Kazakhstan State University, Department of mechanical engineering, Ust-Kamenogorsk, Kazakhstan

Assylkhan Mazdubay
Toraigyrov University,
Mechanical Engineering faculty,
Department of Metallurgy,
Pavlodar city, Kazakhstan

\author{
Sayagul Tussupova \\ Toraigyrov Pavlodar State \\ University, Department of \\ mechanical engineering, \\ Pavlodar, Kazakhstan
}

\section{Aigerim Izotova}

Karaganda Technical University, Mechanical Engineering faculty, Department of Foreign Languages, Karaganda city, Kazakhstan

\section{Almat Sagitov \\ Karaganda State Technical University, Department of Technological equipment, mechanical and standardization, Karaganda, Kazakhstan}

Key words: pipe fittings, stop valve, gate valve, conical friction cutter, hole milling, multi-pass welding

Cite article:

Riza, G., Karibek, S., Sayagul, T., Olga, Z., Sergey, M., Aigerim, I., Aizhan, T., Assylkhan, M., \& Almat, S. [2021]. Research and quality assurance of the large valves manufacture for trunk pipelines. Journal of Applied Engineering Science, 19(1), 24 - 29. DOI:10.5937/jaes0-23523

Online aceess of full paper is available at: www.engineeringscience.rs/browse-issues 


\title{
RESEARCH AND QUALITY ASSURANCE OF THE LARGE VALVES MANUFACTURE FOR TRUNK PIPELINES
}

\author{
Riza Gabdyssalyk ${ }^{1}$, Karibek Sherov²*, Sayagul Tussupova ${ }^{3}$, Olga Zharkevich ${ }^{2}$, Sergey Mirgorodskiy', \\ Aigerim Izotova ${ }^{4}$, Aizhan Taskarina ${ }^{5}$, Assylkhan Mazdubay ${ }^{5}$, Almat Sagitov ${ }^{2}$ \\ ${ }^{1} D$. Serikbayev East Kazakhstan State University, Department of mechanical engineering, \\ Ust-Kamenogorsk, Kazakhstan \\ ${ }^{2}$ Karaganda State Technical University, Department of Technological equipment, mechanical and \\ standardization, Karaganda, Kazakhstan \\ ${ }^{3}$ Toraigyrov Pavlodar State University, Department of mechanical engineering, Pavlodar, Kazakhstan \\ ${ }^{4}$ Karaganda Technical University, Mechanical Engineering faculty, Department of Foreign Languages, \\ Karaganda city, Kazakhstan \\ ${ }^{5}$ Toraigyrov University, Mechanical Engineering faculty, Department of Metallurgy, Pavlodar city, \\ Kazakhstan
}

This article deals with analysis of the production state of pipeline valves in the Republic of Kazakhstan (RK). As a result of the study, it was found that to ensure high reliability and complete environmental safety of the communications system of pipeline transport, it is necessary to improve the quality of manufacturing pipeline valves and other elements of the pipeline transport system by using new promising developments in the field of mechanical processing, assembly, welding, etc. The relevance of the study is the issues of the large valves manufacturing for pipelines. The design and classification of pipelines, pipe fittings, in particular, valves, have been investigated. It has been established that the most difficult and time consuming to manufacture among pipeline valves is the design of gate valves. The technology of manufacturing large-sized gate valves in the conditions of the Ust-Kamenogorsk reinforcement plant has been investigated and the issues of quality and accuracy assurance in the manufacture of a box assembly have been identified. The results of experimental studies of the milling process of a tapered surface have shown the possibility of using a friction cone cutter for machining holes with curvilinear surfaces of a semi-hull of a large-sized sliding gate valve.

Key words: pipe fittings, stop valve, gate valve, conical friction cutter, hole milling, multi-pass welding

\section{INTRODUCTION}

In the Republic of Kazakhstan (RK), one of the main technical tasks for the transportation of oil and oil products, steam, cold and hot water and various other liquid neutral and aggressive working media is the creation of a highly organized communications system for pipeline transportation, ensuring high reliability and complete environmental safety. This can be achieved by creating and manufacturing high-quality pipeline valves and other elements of the pipeline transportation system, through use of new and promising developments in the field of mechanical processing, assembly, and welding. Pipelines and their branches (with an inclusive diameter of up to $1420 \mathrm{~mm}$ ) inclusive with an overpressure of the transported product not exceeding $10 \mathrm{MPa}$, intended for transportation [1, 2], belong to the main pipelines:

- natural gas or petroleum hydrocarbon gas from the areas of their production to the point of consumption;

- artificial hydrocarbon gas from the place of production to the place of consumption;

- liquefied hydrocarbon gases (propane, butane and their mixtures) from the production sites to the consumption sites;
- oil from the areas of its production (from head pumping stations) to places of consumption (oil depots, transshipment bases, oil refineries or petrochemical complexes, loading points, separate industrial enterprises and ports);

- oil products from the places of their production (oil refineries or petrochemical complexes) to the places of consumption (oil depots, transshipment bases, loading points, individual industrial enterprises and ports);

- marketable products within the head and intermediate gas compressor, oil and petroleum pumping stations, underground gas storage stations, gas distribution stations, and metering points.

Gate valves are used when a straight-line flow of fluid and minimum restriction is desired. Gate valves are so named because the part that either stops or allows flow of fluid through the valve acts somewhat like the opening or closing of a gate and is called, appropriately, the gate [3]. A gate valve has the structure of a valve, with the valve in the form of a disk. The gate valve moves along the sealing surfaces of the housing seat, and perpendicular to the movement of the working medium flow. This type of device refers to parallel valves, the design of which assumes that the sealing surfaces are parallel to 
each other. The advantages of the gate valve include the simplicity of its design, low hydraulic resistance, and the ability to use for environments with solid inclusions. The disadvantages of these valves include their low degree of tightness and a high construction height [4 - 6].

\section{Relevance of the research}

There are large plants such as KazArmatura Plant (Temirtau c.), Pavlodar Plant of Valve Fittings (Pavlodar c.), Atyrau Pipe Fittings Plant (Atyrau c.), and Ust-Kamenogorsk Valve Plant (Ust-Kamenogorsk c.), which serve as consumers in Kazakhstan, and as such, are the largest energy-producing, oil refining and metallurgical enterprises of the Republic of Kazakhstan and the countries of independent states. Studies on the production of these plants have shown that the design of gate valves is the most difficult and time consuming to manufacture among pipeline valves. Figure 1 shows a sketch and a photo of a gate valve manufactured by the Ust-Kamenogorsk Valve Plant.

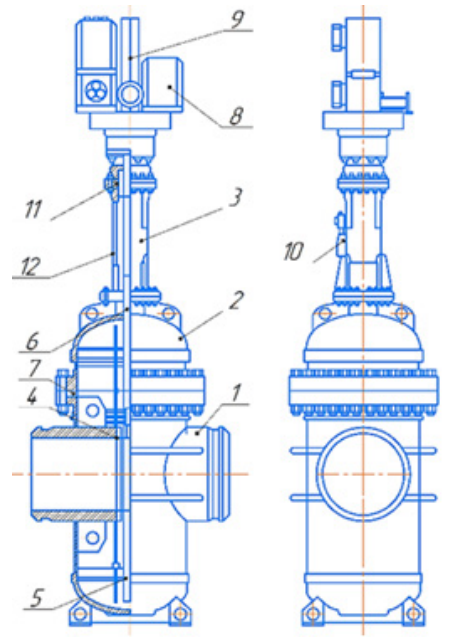

a)

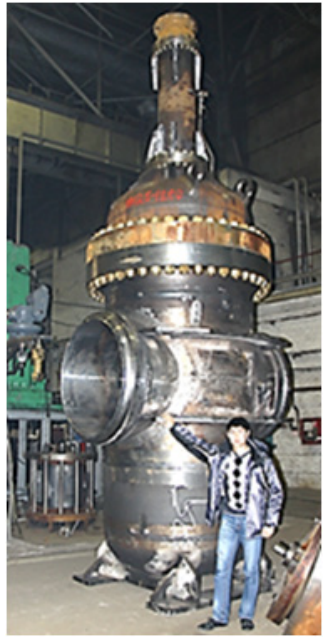

b)
Figure 1: A sketch and a photograph of the gate valve. (a) a sketch of the slide gate; (b) a photograph of the slide valve assembly; 1 - a case; 2-a cap; 3 - a rack; 4 - a seat; 5-a gate; 6 - a spindle; 7 - a ring sealing; 8 - an electric drive; 9 - a casing; 10 - a drainage piping; 11 - a point knot; 12 - a cover protective piping drainage

Studies on the manufacturing technology of pipeline valves have shown that there is a problem of quality assurance in their manufacture, and particularly in the manufacture of the gate valves. The manufacturing techniques for gate valves under the conditions of the Ust-Kamenogorsk Valve Plant (Ust-Kamenogorsk c.) provide for a welded construction of the gate valve, and present the following problems:

- the accuracy of the docking of the details of the nozzle and the housing box for the connection by welding;

- the quality and accuracy of the machining of the assembly units of the valve, specially the machining of the end surfaces of the branch pipes mating with the surface of the gate and the holes for the branch pipe in the boxes of the housing and further cutting the edge under the weld;

- the quality of weldability of parts (chiefly pipes and housing boxes), and the accuracy and quality of assembly of the gate valve depends on the accuracy of the connection.

Solving the above problems is pertinent task.

\section{EXPERIMENTAL}

\section{Discussion of the problem and determination of the their solution}

A gate valve consists of a housing with a lid, a shutter and connecting pipes extending from the housing, which the device is connected to via-the pipeline. In the valve housing there is a hole through which the working medium passes [7]. The gate valve is placed inside the case and moves up and down, like to a knife's motion. The results of the study of the manufacturing technology of large gate valves in the conditions of the Ust-Kamenogorsk Valve Plant show that to improve the quality of workmanship and ensure durability, strength, density and tightness of joints and parts, it is necessary to use a welding robot to automate assembly and welding works when assembling the node case. In welding robots, a pulse-arc welding process is provided, which allows welding with the reverse formation of the root of the seam. Welding with robots requires a high precision of assembly is required; this necessitates the mechanical preparation of edges in the box of the housing for welding on a computer numerical control machine (CNC machine). Figure 2 shows the gate valve housing box.

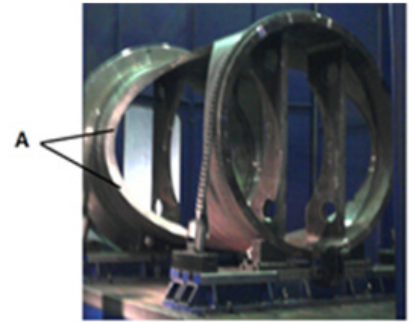

a)

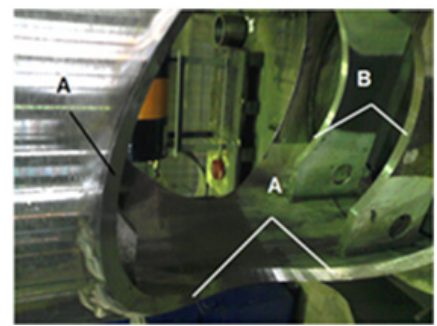

b)
Figure 2: The box case of the gate valve:

$A, B$ - surfaces exposed for processing

Quality performance of the welded joint "nipple-body structure" of the slide gate valve is through penetration of the weld, ensuring the reverse formation of the weld root roll. This can be achieved only with high precision machining of the hole in the body structure (Figure 2, surfaces $A$ and $B$ ), taking into account the need to ensure the blunting of the edge and a uniform gap between the joined elements during assembly for welding. Figure 3 shows a sketch of the gate valve housing box.

Figure 4 shows the half-body structure of the gate valve subassembly. 


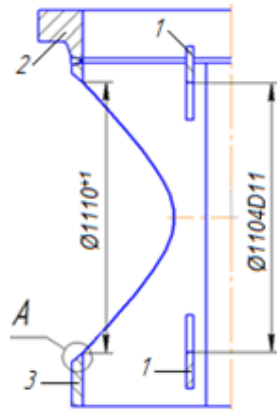

a)

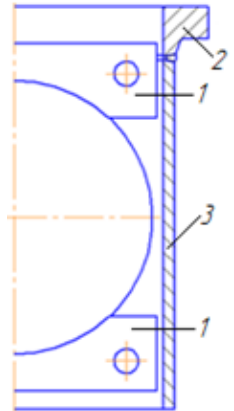

b)

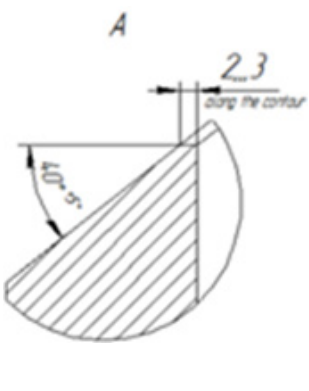

c)
Figure 3: A body structure of the gate valve: a) a side view; b) a front view; c) a view $A$; 1 - ribs; 2 - a flange; 3 - a shell

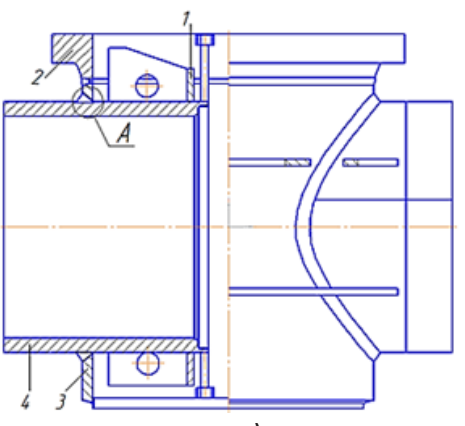

a)

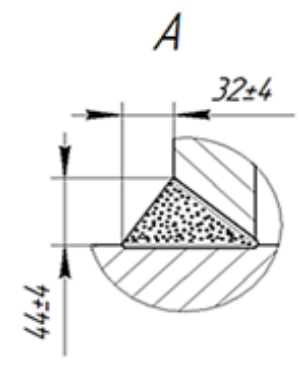

b)
Figure 4: Subassembly half-body structure of the gate valve: a) a side view; b) a type $A ; 1$ - ribs; 2 - a flange; 3 - a shell; 4 - a pipe

The valve housing body structure (Figure 3 ) consists of connecting two parts of a shell (3) and flange (2). After assembling the body structure assembly into the inner strips, the rib (1) parts are welded. The hole $\varnothing 1110+1$ with a curved surface is cut out by firing and further processed along the contour for the weld (Figure $3 b$ ). The nozzle part is installed into the holes $\varnothing 1110+1$ and $\varnothing 1104 \mathrm{D} 11$, welded along the contour in a continuous arc using the MIG / MAG method. According to the drawing, a hole with a curved surface has a $1 \mathrm{~mm}$ tolerance. With proper basing of the nozzle, it should have a diameter 3 $\div 3.5 \mathrm{~mm}$ gap (with clearance) for welding. However, it is not possible to ensure a uniform clearance over the diameter of the nozzle within the tolerance, due to the poor quality of the hole machining and the outer diameter of the nozzle, as well as the difficulty of ensuring the coaxiality of the nozzle and the holes $(\varnothing 1110+1$ and $\varnothing 1104 \mathrm{D11}$ ) of the half-box (Fig. 3a and Fig. 4a) during assembly. If the gap is uneven in the diameter of the nozzle, it is impossible to ensure the quality of welding and reverse formation of the weld root bead.

To solve this problem, researchers noted [8] the need to develop advanced technology for machining holes with a curved surface. Based on the results obtained in [9, 10] and conducted studies, a method of thermo friction milling and the design of a special conical friction cutter for machining holes with curved surfaces of the half-body subassembly have been developed.

\section{Technique and equipment research}

The study was conducted by experimental and theoretical methods. The theoretical studies applied the basic concepts of such sciences as the theory of cutting materials, mechanical engineering technology, design of cutting tools, metal technology, welding technology, research planning and the theoretical foundations of surfacing [11]. Experimental studies were carried out using technological equipment from the "Technological equipment, mechanical engineering and standardization" at Karaganda State Technical University. The roughness and hardness of the treated surfaces were measured using electronic devices. Figure 5 shows a JTM-1050 VSE JET vertical milling machine and a conical friction milling cutter.

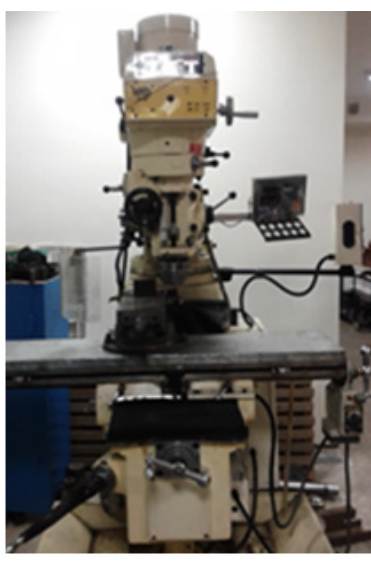

a)

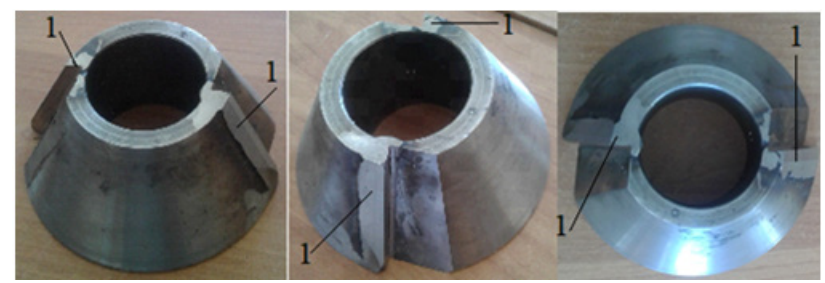

b)
Figure 5: JTM-1050 VSE JET vertical milling machine and cone friction cutter:

(a) vertical milling machine JTM-1050 VSE JET; (b) photograph of a conical friction cutter; 1 - weld teeth

To increase the wear resistance of the friction cone cutter, the cutting parts of the tool were deposited with a STOODY M7-G surfacing material with high hardness and temperature resistance. Table 1 shows the chemical composition and hardness of the material.

Table 1: Chemical composition and hardness of the STOODY M7-G surfacing material, $\%$

\begin{tabular}{|c|c|c|c|c|c|c|c|}
\hline $\mathrm{C}$ & $\mathrm{Cr}$ & $\mathrm{Mn}$ & $\mathrm{Mo}$ & $\mathrm{V}$ & $\mathrm{W}$ & $\mathrm{Fe}$ & Hardness \\
\hline 1,0 & 4,0 & 0,4 & 9,0 & 2,0 & 2,0 & basis & $58-66$ HRC \\
\hline
\end{tabular}

Surfacing was performed at the laboratory of the Kazakhstan Institute of Welding at Karaganda State Technical University. For processing we used blanks made of Steel 20 material with dimensions $120 \times 80 \times 40 \mathrm{~mm}$. 




a)

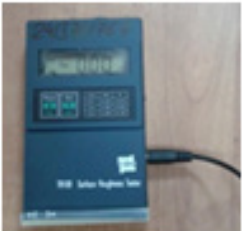

b)

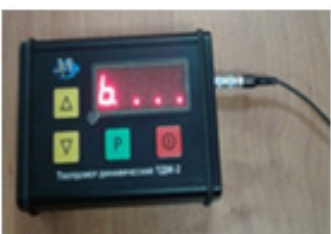

c)
Figure 6: Slugs for processing and electronic devices for measuring the roughness and hardness of machined surfaces:

a) slugs for processing from steel 20; b) portable meter (profilometer) of the TR 100 roughness;

c) a compact dynamic hardness tester TDM-2

Figure 6 shows machined work pieces and electronic devices for measuring the roughness and hardness of machined surfaces.

\section{Planning of experiment}

An experiment plan of 23 type was drawn up to determine the dependence of surface roughness $(Y)$ on the spindle rotation frequency $\left(X_{1}\right)$, feed rate $\left(X_{2}\right)$ and cutting depth $\left(X_{3}\right)$. An estimate of the uniformity of the experiments was determined, and the regression coefficients of the first-order approximating polynomial were found, taking into account the effects of pairwise interaction [12]. An interpretation of the results obtained in terms of the object of study is given below. The adequacy of the regression equation found was checked. The calculations were performed in Mathcad. Table 2 shows the initial values of the physical factors $X_{1}, X_{2}, X_{3}$.

Table 2: Initial values of physical factors $X_{1}, X_{2}, X_{3}$

\begin{tabular}{|c|c|c|c|c|c|}
\hline \multirow{2}{*}{$X_{1}$} & \multirow{2}{*}{$X_{2}$} & $X_{3}$ & \multicolumn{3}{|c|}{$Y$} \\
\cline { 4 - 6 } & & & 1 & 2 & 3 \\
\hline-1 & -1 & -1 & 12 & 7 & 11 \\
\hline 1 & -1 & -1 & 3,5 & 10 & 1,8 \\
\hline-1 & 1 & -1 & 1,3 & 1,25 & 9,5 \\
\hline 1 & 1 & -1 & 1,3 & 1,3 & 1,5 \\
\hline-1 & -1 & 1 & 1,25 & 1,25 & 1,4 \\
\hline 1 & -1 & 1 & 1,5 & 1,5 & 1,35 \\
\hline-1 & 1 & 1 & 5 & 1,25 & 3,1 \\
\hline 1 & 1 & 1 & 12,5 & 6,5 & 6,8 \\
\hline
\end{tabular}

After combining the data in each column, respectively, new factor columns were formed $\left(X_{1}, X_{2}, X_{3}\right)$ :

$$
X_{1}=\left(\begin{array}{c}
-1 \\
1 \\
-1 \\
1 \\
-1 \\
1 \\
-1 \\
1
\end{array}\right) \quad X_{2}=\left(\begin{array}{c}
-1 \\
-1 \\
1 \\
1 \\
-1 \\
-1 \\
1 \\
1
\end{array}\right) \quad X_{3}=\left(\begin{array}{c}
-1 \\
-1 \\
-1 \\
-1 \\
1 \\
1 \\
1 \\
1
\end{array}\right)
$$

As a result of the calculations, coded factors were obtained that are necessary for drawing up the experiment plan, and the values of the factors and their levels were calculated, which are given below in Table. 3

Table 3: Values of factors and their levels

\begin{tabular}{|c|c|c|c|}
\hline \multirow{2}{*}{ Dimensions } & \multicolumn{3}{|c|}{ Factor } \\
\cline { 2 - 4 } & $\begin{array}{c}\text { Spindle rotation } \\
\text { frequency } X_{1}\end{array}$ & $\begin{array}{c}\text { Feed } \\
\text { rate } \\
X_{2}\end{array}$ & $\begin{array}{c}\text { Cutting } \\
\text { depth } \\
X_{3}\end{array}$ \\
\hline Main level $X_{i}$ & 1500 & 22,5 & 1,25 \\
\hline Variation interval $I_{i}$ & 1000 & 17,5 & 0,75 \\
\hline Top level $X_{\text {imax }},+1$ & 2500 & 40 & 2 \\
\hline Lower level $X_{\text {imin }},-1$ & 500 & 5 & 0,5 \\
\hline
\end{tabular}

As a result, a mathematical model of roughness was determined:

$$
\begin{aligned}
Y & =a_{0} X_{0}+a_{1} X_{1}+a_{2} X_{2}+a_{3} X_{3} \\
& +a_{12} X_{1} X_{2}+a_{13} X_{1} X_{3}+a_{23} X_{2} X_{3}
\end{aligned}
$$

\section{Results and discussions}

Figure 7 shows the process of milling a tapered surface, using a tapered friction cutter with surfacing from a weld grade STOODY M7-G, as well as machined surfaces of the work pieces under various cutting conditions.

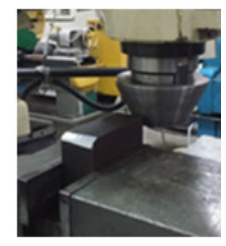

a)

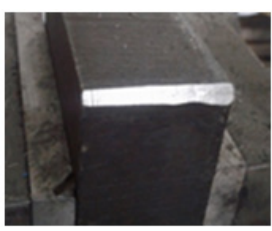

c)

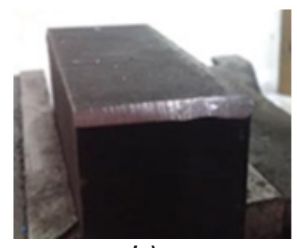

b)

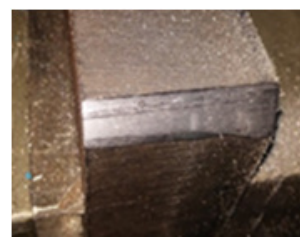

d)
Figure 7: The process of milling a tapered surface and machined surfaces of the work pieces under different cutting conditions:

a) the process of milling;

b) spindle rotation frequency $n s=1500 \mathrm{rpm}$, feed rate Smt $=80 \mathrm{~mm} / \mathrm{min}$, cutting depth $t=1 \mathrm{~mm}$;

c) spindle rotation frequency $n s=2500 \mathrm{rpm}$, feed rate Smt $=40 \mathrm{~mm} / \mathrm{min}$, cutting depth $t=1 \mathrm{~mm}$;

d) spindle rotation frequency $n s=2000 \mathrm{rpm}$, feed rate Smt $=60 \mathrm{~mm} / \mathrm{min}$. cutting depth $t=1 \mathrm{~mm}$

Milling the tapered surface was carried out by the following cutting conditions: ns $=500 \div 2500 \mathrm{rpm}$; Sst $=20 \div 100 \mathrm{~mm} / \mathrm{min}$; $\mathrm{t}=1 \div 1.5 \mathrm{~mm}$. Figure 8 shows the chips produced at different cutting conditions. 


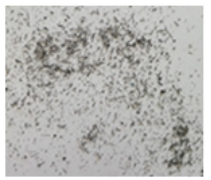

a)

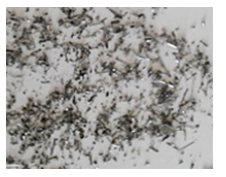

c)

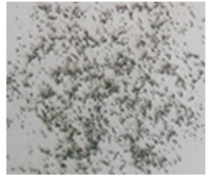

b)

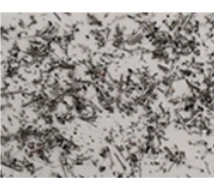

d)
Figure 8: Chips obtained with different cutting conditions:

(a) spindle rotation frequency $n s=1000 \mathrm{rpm}$, feed rate $S \mathrm{mt}=20 \mathrm{~mm} / \mathrm{min}, t=1 \mathrm{~mm}$;

b) spindle rotation frequency $n s=1500 \mathrm{rpm}$, feed rate Smt $=40 \mathrm{~mm} / \mathrm{min}$, cutting depth $t=1 \mathrm{~mm}$;

c) spindle rotation frequency $n s=2000 \mathrm{rpm}$,

feed rate $S \mathrm{mt}=60 \mathrm{~mm} / \mathrm{min}$, cutting depth $t=1 \mathrm{~mm}$;

d) spindle rotation frequency $n s=2500 \mathrm{rpm}$,

feed rate $S m t=60 \mathrm{~mm} / \mathrm{min}$, cutting depth $t=1 \mathrm{~mm}$

Figure 9 shows the graphs of quality indicators from cutting conditions.

The results of experimental studies of the process of milling with a conical cutter of friction with overlaying showed that with increased cutting speed and a decreased feed, all the quality indicators of the machined surface improve. However, an excessive feed reduction adversely affects processing performance.

As a result of the experimental studies, the optimum cutting conditions were established: spindle rotation frequency $n_{s}=2500 \mathrm{rpm}$; feed rate $S_{m t}=40 \mathrm{~mm} / \mathrm{min}$. When processing on these modes, the roughness of the processed surface $R_{a}=1.75 \mathrm{~m} \mu \mathrm{m}$ (Figure 9a, straight line 2) was achieved, and the required hardness of the treated surface $H B>130$ was also provided (Figure 9b, straight line 2). The processed surface of the work piece is shown on Figure $7 b$.

When milling at different cutting conditions, drain chips of various sizes were formed (Figure 8). At the smallest feed rates of $S_{m t}<40 \mathrm{~mm} / \mathrm{min}$, small chips were formed (Figure $8 a, b)$. With an increase in feed rate $S_{m t}>40 \mathrm{~mm} / \mathrm{min}$, an increase in chip sizes was observed (Figure 8c, d).

The results of experimental studies of the process of milling a conical surface using a conical mill equipped with carbide plates and a conical friction cutter with surfacing from STOODY M7-G surfacing material showed the possibility of using them for machining holes with curvilinear surfaces of the semi-hull of a large gate valve.

The application of the proposed technology improves the quality and accuracy of machining of holes with a curved surface and allows reducing the size of the gap due to tighter tolerances on the diameter of the opening of the half-body box. In this case, a uniform clearance is achieved across the nozzle diameter, which will allow the use of MIG-MAG multipass welding $[13,14]$ with the use of a robotic complex according to a predetermined program, taking into account the production of a main

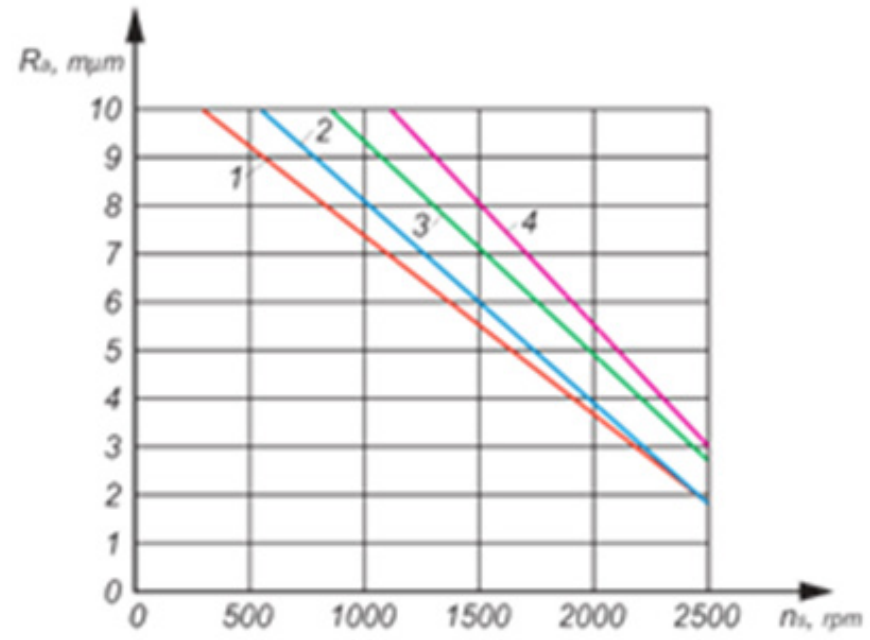

a)

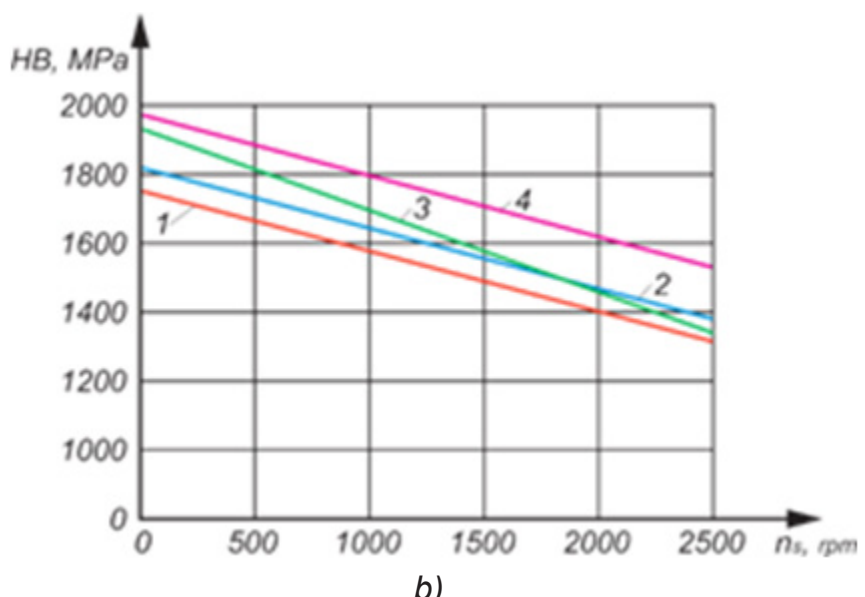

Figure 9: Graphs of dependence of quality indicators on cutting conditions:

a) pendence of roughness on spindle rotation frequency;

b) dependence of hardness on spindle rotation frequency; 1 - Smt $=20 \mathrm{~mm} / \mathrm{min} ; 2$ - Smt $=40 \mathrm{~mm} / \mathrm{min}$;

3 - Smt=60mm/min; 4 - Smt $=80 \mathrm{~mm} / \mathrm{min} ; t=1 \mathrm{~mm}$

roller with a reverse formation using the Surface Tension Technology method [15].

Furthermore, robotization will allow for modernization of production, simultaneously improving manufacturing quality, productivity, and improvement of product competitiveness and reduce labor intensity.

\section{CONCLUSIONS}

The main conclusions drawn from the study are:

The analysis of the state production of pipeline valves in the Republic of Kazakhstan was carried out. It was found that to ensure high reliability and complete environmental safety of the communications system of pipeline transportation, it is necessary to improve the quality of manufacturing pipeline valves and other elements of the pipeline transportation system by using new promising developments in the field of mechanical processing, assembly, and welding, among other fields. 
The design and classification of pipelines, pipe fittings and valves, in particular gate valves, were investigated.

The analysis of the production of pipeline valves in the conditions of the plants in the Republic of Kazakhstan, particularly the Ust-Kamenogorsk valve plant, was carried out and revealed that the design of large-sized gate valves is the most difficult and labor-intensive to manufacture among pipeline valves.

The manufacturing technology of gate valves in the conditions of the Ust-Kamenogorsk reinforcement plant has been investigated and problems of quality and accuracy assurance in the manufacture of the box housing have been identified. In the process, the researchers also identified the objectives of the study to solve these problems.

It has been established that the bottlenecks most subject to rapid wear are the mating surfaces of the saddle and gate parts. However, to identify the causes of wear of the mating surfaces of this site, it was necessary to conduct additional research on the technology of their manufacture.

To solve this problem, a special conical friction milling cutter with surfacing from STOODY M7-G surfacing material was developed and manufactured.

When machining the friction cutter, high results of the quality of the processed surface $R_{a}=1.25 \div 3.0$ microns were achieved. It has been established that an increase in cutting speed has a positive effect on quality indicators, while on the contrary, an increase in feed is reduced. The optimum cutting conditions are revealed: rotation of a spindle $n_{s}=2500 \mathrm{rpm} ; S_{m t}=40 \mathrm{~mm} / \mathrm{min}$.

During processing, drain chips were formed, and high-quality crushing of chips was carried out, as well as an increase in feed resulting in an increase in chip sizes. The results of experimental studies of the milling process of a conical surface using a conical friction cutter with surfacing from surfacing material STOODY M7-G have shown the possibility of its use for machining holes with curvilinear surfaces of a semi-hull large-sized gate valve.

\section{REFERENCES}

1. Shammazov, A.M., Alexandrov, V.N., Golyanov, A.I. and others. (2003). Design and operation of pump and compressor stations. LLC "Nedra-Business Center", Moscow, 208p.

2. Mustafin, F.M., Gumerov, A.G., Konovalov, N.I. (2003). Pipe fittings. UGNTU, Ufa, 182p.

3. Dharmarao, S. (2014). Stress analysis of gate valve by ANSYS. Conference: DAV International Journal, At Solapur, 3 (1), P.1623 - 1630.

4. Gurevich, D.F. (1984). Calculation and design of pipe fittings. Scientific publication. Mechanical Engineering, Moscow, 315p.

5. Persion, A.A., Garus, K.A. (1987). Installation of pipelines. Reference worker. Publishing house "Budivelnik". Kiev. 208p.
6. Chemodurov, Yu. K. (2009). Pipeline transportation of gas, oil and petroleum products. Belarus, Minsk, $214 p$.

7. Sherov K.T., Gabdyssalyk, R. (2018). Analysis and research of the problem of manufacturing large valves for main pipelines. University proceedings, No 1, P.13-17.

8. Sherov, K.T., Sikhimbayev, M.R., Sherov, A.K., Mazdubai, A.V., Rakishev, A.K., Abeuova, A.M. (2017). Matematical modeling of thermofrictional milling process using ANSYS WB software. Journal of Theoretical and Applied Mechanics, Sofia, Vol. 47, No. 2. P. 24-33. https://doi.org/10.1515/jtam-20170008

9. Sherov, K.T., Sikhimbayev M.R., Donenbayev B.S., Sagitov A.A., Ainabekova S.S. (2017). Experimental Research of Rotational-and-Frictional Boring of Big Holes in Large Parts/Journal of Theoretical and Applied Mechanics, Sofia, Vol. 47, No. 4 pp.23-36. https://doi.org/10.1515/jtam-2017-0018

10. Sherov, K.T., Sikhimbayev, M.R., Nasad, T.G., Absadykov, B.N., Izotova, A.S., Okimbayeva, A.E., Kuanov, I.S. (2020). The research of the steel cutting blade reliability for thermo-frictional processing. News of the National Academy of Sciences of the Republic of Kazakhstan. Series of geology and technical sciences. 2020. Volume 1, Number 439, P.122 - 130. https://doi.org/10.32014/2020.2518-170X.15

11. Borza, S.I., Beju, L.D. (2012). Modern Methods of Education, Research and Design Used in Mechanical Engineering: Chapter (PDF Available). P.589614. DOI: $10.5772 / 35343$

12. Golberg, M., Cho, H.A. (2010). Introduction to Regression Analysis. WIT press, Las Vegas, 452p. https://www.witpress.com/books/978-1-85312-624-6

13. Gabdyssalyk, R., Lopukhov, Yu.I. (2014). Improving the manufacturability and service properties of dispersion-hardening steels in the MAG overlaying conditions for thermal power fittings. Bulletin of the D. Serikbayev East Kazakhstan State Technical University, No 4. P.64-70.

14. Gabdyssalyk R., Lopukhov Yu.I. (2015). Improving the erosion properties of dispersion - hardening steel in the MAG overlaying conditions for thermal power fittings. Bulletin of the East Kazakhstan State Technical University. D. Serikbaeva, No 2. P. 63-69.

15. Zhang, X. (2013). Handbook of laser welding technologies. Cambridge: Woodhead Publishing Limited, $654 p$.

Paper submitted: 09.10.2019.

Paper accepted: 08.07.2020.

This is an open access article distributed under the CC BY 4.0 terms and conditions. 